\title{
Extremism and the Psychology of Uncertainty
}

\author{
Michael A. Hogg and Danielle L. Blaylock
}

Chichester: Wiley-Blackwell, 2012

ISBN: 987-1-4443-3128-8

Hardback - 328pp - £70

\section{Reviewed by Dr. Rusi Jaspal}

Michael Hogg and Danielle Blaylock highlight the growing societal concern of extremism and the need to understand its social and psychological antecedents. Based on the Extremism and the Psychology of Uncertainty conference at Claremont Graduate University, their edited volume presents eighteen chapters which collectively aim to examine the relation between uncertainty and extremist phenomena. The volume is divided into three parts. Part One presents relevant theories and concepts; Part Two features five chapters that explore individuals and groups; Part Three presents five further chapters relating to groups and society. While the volume is broad in scope and provides fascinating insights into advances in the field of uncertainty, its contribution to extremist phenomena is less clearly defined.

\section{Part One}

The first chapter by Kruglanski and Orehek examines the human need for certainty and how this in turn relates to perceptions and behaviour towards outgroups. The authors argue that human beings have an epistemic need for firm knowledge (cognitive closure), which they invoke in order to understand responses to terrorism, arguing that "if terrorism breeds insecurity and uncertainty, it should elevate people's need for cognitive closure" (p. 10). Their chapter provides a holistic view of extremism among both perpetrators and victims.

Michael Hogg draws upon Uncertainty-Identity Theory and Social Identity Theory in order to argue that social identification can produce extremism under conditions of uncertainty, that is, feelings about uncertainty about who one is, can easily become bigotry, intolerance and violence. One particularly interesting element of Hogg's chapter is his discussion of ideology and orthodoxy in extremist group thinking. However, despite calls for social psychologists to incorporate ideology in their analyses of social psychological phenomena, the discipline has been slow to do so. Some methodological guidance regarding the ways in which social psychologists interested in uncertainty and extremism could empirically examine the roles of ideology and orthodoxy would have been useful.

Dominic Abrams argues in his chapter that extremity within groups is a normal and essential aspect of group life. Moreover, for Abrams, while extremism can both arise from and engender uncertainty, "it can be a reference point for a strong and clear norm" (p. 51). The chapter makes a sound contribution to our understanding of how people may defend prescriptive ingroup norms.

In chapter four, Travis Proulx roots his analysis of the "psychology of the absurd" in a discussion of how existentialists addressed extremist beliefs. Proulx proceeds to outline the Meaning Maintenance Model as a means of better explaining the psychology of the absurd. While the chapter provides interesting insights into meaning and uncertainty particularly within the context of the self, it does not examine the notion of extremism in any explicit manner. The link between uncertainty and extremism is implicit and left to be inferred by the reader.

Kees van den Bois and Annemarie Loseman, the authors of chapter five, examine the role of personal uncertainty (which they differentiate from informational certainty) in explaining why individuals can resort to "extreme" ways of defending their own cultural values. They argue that uncertainty is likely to be more of an issue for individuals living in "delayed-return cultures," and suggest that the experience of personal uncertainty can result in threat or avoidance responses. However, the chapter seems not to acknowledge other potentially important forms of group identity threat which can in turn induce avoidance responses - some of these are discussed in Staub's chapter (see below).

In chapter 6, Jost and Napier present three empirical studies to assess the uncertainty-threat model of political conservatism, which proposes that psychological needs to manage uncertainty threat are associated with political conservatism rather than extremism in general. Although their 
findings provide important insights into political conservatism, the implications for extremism are less clear.

\section{Part Two}

Siegel and colleagues present results which suggest that willingness among their student participants to endure physical harm in order to achieve popularity was observable among those individuals whose level of self-uncertainty was high and who regarded popularity as a method of reducing selfuncertainty. However, it is not entirely clear how their findings "may help shed light on the behaviour of extremists who willingly sacrifice their lives for the causes with which they have identified" (p. 126).

Landau, Rothschild and Sullivan propose that political and religious extremism may be associated with the desire to minimise existential uncertainty, that is, uncertainty about the possibility of achieving a significant life and the methods for doing so, and argue that individuals minimise uncertainty by creating and adhering to "concrete, fetishized conceptions of the world and themselves" (p. 140). The authors convincingly argue that a key feature of extremist ideology is a construction of reality in which everything is dichotomously labelled as either good or evil, that is, fetishism.

In the next chapter, McGregor, Nash and Prentice summarise experimental research on compensatory conviction and reactive approach motivation in order to explain the relation between anxious uncertainty resulting from goal frustration and religious zeal. Although they "hope that nonreligious readers will resist the temptation to dismiss all religious devotion as antisocial ignorance" (p. 161), the authors do not clearly distinguish "antisocial religious zeal" and a more psychologically healthy "religious devotion." Consequently, it is not easy to decipher the contribution of the chapter to understanding (religious) extremism, in particular.

In chapter 10, Giner-Sorolla and colleagues argue that acts of violence can provide extremists with greater certainty about their own acts and their general situation. They conclude that group identification can justify extremist violence against dehumanised outgroups when the violence is moralised and employed as a means of accentuating self-certainty. Commendably, the authors bring together the literatures on dehumanisation, demonization and certainty in a novel attempt to understand the perpetration of extremist violence.

In his chapter on uncertainty and extreme positive acts towards the outgroup, Todd Pittinsky describes a model that sheds light on the role of allophilia in encouraging extreme positive behaviour towards outgroups, despite the potential dominance of negative norms. The chapter's contribution to understanding extremism is unclear - it appears that the extremism is employed as an adverb in order to describe the degree to which behaviour manifested towards an outgroup can be positive, rather than examining the notion of extremism itself.

\section{Part Three}

In their chapter on uncertainty, insecurity and ideological defense of the status quo, Federico and Deason examine the "extremitizing" role of political expertise, rather than examining extremism as a societal problem. This is similar to the position adopted by Pittinsky. One key assertion in the chapter is that individuals who are intolerant of uncertainty are more likely to manifest more extreme ideological defense of the status quo, provided that they also score highly on political expertise.

Merolla and colleagues make an important contribution to understanding uncertainty and extremism. They show that individuals who score highly on authoritarianism and need for closure are more likely to manifest extremism when they feel threatened (e.g. from terrorism). In chapter 14, we gain some insight into how rhetorical from the institutional level can feed into uncertainty at the individual level. Viviane Seyranian provides a fascinating perspective on how powerful leaders can rhetorically exploit uncertainty in order to produce extremist social identities for mobilisation effects. The chapter is a timely examination of how leadership, rhetoric and uncertainty collectively contribute to the emergence of extremism in societies, and provides stimulating ideas for application to a wide range of conflict contexts.

Fathali Moghaddam and Karen Love make a similarly lively and exciting contribution to the volume. They explore the relation between collective uncertainty and extremism by arguing that extremism and terrorism constitute example of "dysfunctional defense mechanisms," which groups adopt during times of instability, insecurity and uncertainty. One of the main strengths of the chapter lies in its consistent attention to existing real-world problems concerning extremism and terrorism the authors do not lose sight of the practical importance of this area, consistently moving beyond theoretical speculation to real-world application.

The final chapter of the volume is an excellent piece by Ervin Staub on uncertainty, and the roots and prevention of genocide and terrorism. Staub focuses upon the socio-psychological 
processes which lead to genocide and terrorism. The author argues that an increase in uncertainty is likely to be conducive to violence, while a reduction in uncertainty (and the fulfilment of basic needs through constructive means) is likely to be conducive to the prevention of violence and reconciliation of hostile groups.

Overall, this is a fascinating volume, which aims to examine the interface of uncertainty and extremism. While most chapters seem to examine uncertainty in more depth, leaving its link to extremism to be inferred by the reader, others engage more readily with the theoretical and empirical relations between them. This weakness in the volume may be attributed partly to the general inconsistency in how "extremism" is conceptualised by the contributors. Although the volume claims to examine distinct levels of human interdependence - individual, group and societal - how these levels relate to one another in the context of uncertainty and extremism is not fully fleshed out. Nonetheless, the volume does make some important contributions to the fields of uncertainty and extremism and will therefore be of interest to students and researchers in these areas. 